\title{
EL PROBLEMA DE LA CAUSALIDAD EN EL TAHĀFUT DE AVERROES
}

\author{
Idoia Maiza Ozcoidi \\ UNED. Madrid
}

\section{INTRODUCCIÓN}

El Tahāfut al Tahāfut (Destrucción de la Destrucción) de Averroes supuso la restauración de la filosofía de Aristóteles. Esta obra fue escrita con el fin de refutar punto por punto el Tahäfut al-Falāsifa (Destrucción de los filósofos) de Algacel, para defender la filosofía aristotélica tal y como la interpretaban los comentadores helenísticos menos neoplatonizados y para defender en bastantes ocasiones, aunque no disculpar, a al-Fā $\overline{r a ̄ b i}$ y Avicena.

El enfrentamiento entre ambos pensadores era inevitable. Si Algacel evitó siempre llamarse filósofo y hacerse pasar por tal, Averroes encaminó toda su actividad especulativa a la tentativa de conciliar la filosofía y la religión. Sin embargo, Algacel no fue un mutakallim más. El conocimiento de Dios al que aspiraba este hombre preocupado ante todo de experiencia religiosa se encontraba fuera de las discusiones y de la dialéctica del Kala $\mathrm{m} .{ }^{\mathrm{I}}$ Aunque al teólogo persa le atrajo la sistematicidad de la filosofía por su capacidad de dar cuenta racionalmente de algunas concepciones religiosas fundamentales, la consideró una disciplina además de insuficiente peligrosa, porque arrastraba muchas proposiciones erróneas y.porque el Dios y el mundo designados por ella no podían conciliarse con el Islam. Su propósito fue así el de demostrar que «la razón no basta para conocer todas las cuestiones ni puede descubrir la solución de todos los problemas».2

1 Es difícil descubrir el verdadero pensamiento de Algacel sobre el kalām y más aún su pensamiento definitivo. Algunas veces trata esta ciencia con mucha desconfianza y otras veces le otorga una importancia capital, si bien como ciencia curativa. Para un estudio del lugar que el kalām ocupa en el pensamiento algaceliano Cf. L. Gardet y M. Anawati, Introduction à la théologie musulmane. Essaie de théologie comparée, 3." ed., París, Vrin, 1981, pp. 113-125.

2 Confesiones de Algacel: el salvado del error, trad. Emilio Tornero, Madrid, Alianza, 1989, p. 60. 
A diferencia de los filósofos que partieron de un concepto de Dios aristotélico, pensamiento de pensamiento, y del principio neoplatónico de que de lo Uno sólo se puede originar lo uno, los teólogos musulmanes acentuaron la eternidad de Dios y producción o temporalidad de las criaturas. Se empeñaron además en demostrar racionalmente esta producción de las criaturas como premisa necesaria para demostrar la existencia de Dios, y de ahí vino el choque con la corriente filosófica. Las conclusiones de los filósofos, en especial la de Avicena de una creación necesaria emanatista y eterna, eran inaceptables para los teólogos, pues anteponían a cualquier principio racional el dato revelado de la creación temporal ex-nihilo. Averroes se dio cuenta de aquella mezcla de aristotelismo y neoplatonismo, y aunque criticó a al-Fārābì y Avicena de haber podido evitar las consecuencias denunciadas por Algacel, su solución fue la de una creación necesaria y eterna.

El problema de fondo es, pues, el de si el mundo es eterno o creado en el tiempo. Esta cuestión fue extensamente tratada por Algacel y Averroes en sus Tahăfut. La defensa de una y otra concepción obligaría a ambos pensadores musulmanes a examinar y discutir el problema de la causalidad.

$\mathrm{El}$ argumento clásico utilizado por los teólogos musulmanes para probar la existencia de Dios fue el de la causalidad eficiente a partir del mundo contingente. La razón llegaba a establecer, así, fácilmente la necesidad de un creador. Y puesto que toda acción es una creación ex-nihilo, estos teólogos admitieron una única causa eficiente, Dios, y negaron las causas segundas.

Aristóteles había sostenido que no se daba un efecto natural sin una causa natural que lo determinara. Pues bien, Algacel busca en su Tahăfut acabar con el principio epistemológico que funda esta convicción:

A pesar de que lo causado sea más perspicuo que la causa, que el efecto sea conocido por medio de su causa no es necesario para su existencia, como tampoco es necesario para que exista una causa que sea conocida por medio de su efecto. ${ }^{3}$

Algacel parece anticiparse a Hume al insistir en la costumbre que tiene el hombre de unir causalmente dos fenómenos sin conocer efectivamente el mecanismo de la causalidad:

La continuidad del acaecer habitual de los fenómenos uno tras otro, imprime en nuestra mente una impresión de continuidad tal, que el acaecer habitual aparece como una realidad continua que no puede ser interrumpida. ${ }^{4}$

En realidad es el fundamento ontológico de los seres contingentes el que se viene a poner en duda. Y este ocasionalismo postula al final la existencia absolutamente no contingente y no transeúnte de Dios.

3 Averroes, Tahäfut al-Tahāfut, trad. ingl. de Simon Van den Bergh, Londres, Luzac, 1954, p. 140.

4 Ibid., p. 303. 
La teoría algaceliana de que Dios es el único creador de todos los movimientos y de todos los accidentes sin eficacia de las causas segundas, es la tesis esencial de la filosofía ašarī. Es la producción ad extra de las cosas la que sólo se cuestiona, no su textura ontológica. Todo permanece dominado por la voluntad deliberada de aislar de alguna manera la eficacia divina para salvaguardarla de cualquier posible ataque. Los ašsaríes constatan el nexo que parece conectar a las cosas entre sí, pero niegan que tal nexo sea necesario y lo atribuyen a la-acción de.Dios .5

Para la doctrina del ocasionalismo tiene una importancia capital la cuestión diez y siete del Tahăfut de Algacel, en la cual combate la causalidad de las criaturas defendida por los filósofos:

Para nosotros (los mutakallimūn) no es necesario (ni esencial) el enlace entre lo que se crea causa y lo que se cree efecto. Nada tiene que ver uno con otro [...]. El enlace entre ambas cosas obedece a una disposición divina que las ha creado simultáneamente, pero no es que tal enlace sea necesario e indefectible. ${ }^{6}$

Contra estos ocasionalistas musulmanes Averroes defiende la existencia de las causas segundas con argumentos que se han hecho clásicos en la refutación de todos los ocasionalismos. Y es que el ocasionalismo es una doctrina filosófica con implicaciones en metafísica y en epistemología demasiado graves para el ejercicio de la auténtica filosofía. En metafísica enseña que no hay interacción causal entre los seres, que su contigüidad sólo sirve como «ocasión» para el influjo causal de Dios, única causa verdadera. Y en epistemología el ocasionalismo enseña que los sentidos perciben secuencias regulares de acontecimientos, pero ninguna interacción causal entre ellos. Estas secuencias regulares se explican diciendo que se deben al hábito o costumbre que tiene Dios de hacer seguir unos determinados acontecimientos a otros.

El ejemplo de Algacel de la combustión del algodón por el fuego muestra claramente la posición de estos teólogos musulmanes. Para los filósofos es evidente que la causa eficiente de la combustión es únicamente el fuego, que obra por naturaleza y no por elección. Por el contrario, Algacel afirma que la causa eficiente de la combustión es Dios y que el fuego es un ser inorgánico sin ninguna actividad. En su opinión, no hay pruebas de que el fuego sea agente. Averroes no pudo aceptar esta doctrina tan contraria a la experiencia. Además, suprimidas las causas, se suprime el conocimiento, puesto que la ciencia es la explicación de las cosas por sus causas tal y como sostuvo Aristóteles.

Las ideas de Averroes sobre la causalidad son de una gran importancia, no sólo por el papel que desempeñaron ante los ocasionalistas musulmanes, sino porque como ha subra-

5 Conviene subrayar, sin embargo, que Algacel se movió en torno al problema de la causalidad en una dirección más naturalista de lo que lo hizo al-Aš́ari, llegando a no aceptar algunas premisas básicas de su escuela. Cf. L. E. «Did al-Ghazāî̉ deny causality?», en Studia Islamica, París, G. P. Maisonneuve- Larose, 1978, n. 47, pp. 104-111.

6 Tahāfut al-Tahäfut, ed. cit., p. 316. 
yado S. Gómez Nogales, «ante todo es un concepto de la causalidad mucho más puro que el de la filosofía griega y más afín al concepto cristiano de creación».7

En el Tahäfut, por la naturaleza de los adversarios que tiene que refutar, casi se reduce Averroes a la explicación de la causa eficiente. Recordemos que la noción unívoca de la causalidad eficiente de aquellos teólogos, junto a la no consideración de la causalidad formal, les obligó a no examinar otra causalidad que la absoluta de Dios.

\section{FILOSOFÍA DE LA NATURALEZA. LA CAUSALIDAD DE LAS NATURALEZAS}

Los mutakallimūn aš'aries para fundamentar las verdades iniciales de su teología, se apoyaron en el atomismo, sistema filosófico incompatible con casi todos los principios y

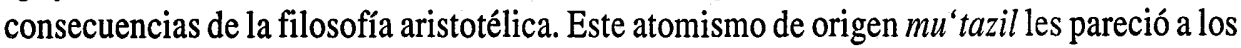
aš́aries que era la filosofía de la naturaleza ideal para salvar racionalmente las exigencias del dogma, particularmente la afirmación de la infinita libertad de Dios y de su total omnipotencia, que hacen de Él el único agente.

El atomismo de los teólogos musulmanes es en realidad el atomismo de algunos filósofos griegos un poco modificado. Es seguro que ya los mu'tázilíes se encontraron con un atomismo elaborado. Pero lo que aquí nos interesa subrayar es que tal modificación y adaptación al dogma musulmán de la creación ex-nihilo que trataban ante todo de salvar, condujo a la supresión o minimización del concepto mismo de causalidad. Todo lo que sucede es porque Dios lo quiere así. La discontinuidad entre las cosas es más real que su continuidad, por lo que conciben la naturaleza como un ámbito de entidades separadas y concretas. Atomizan así la materia, el espacio y el tiempo, y reemplazan la noción de causa por la de simple conexión. Como los accidentes son algo totalmente transeúnte que no puede durar dos instantes seguidos, perecen en cada instante; y como la sustancia no puede existir sin accidentes, al perecer los accidentes perecen también las sustancias. Pero Dios recrea las cosas en todo momento. En esto basaban al principio una de las pruebas de la existencia de Dios: es necesario un Artífice del mundo, porque es necesario recrear el mundo en cada instante. La creación ex-nihilo resulta inmediatamente. La realidad así segmentada y dividida en que consiste la naturaleza encuentra su conexión en la Voluntad divina que crea todas las cosas constantemente y es causa directa de las mismas.

La consecuencia de un tal atomismo es que no existen leyes naturales de las que resulten naturalezas estables en sentido aristotélico. Esas leyes se reducen a hábitos de la mente humana que pueden ser interrumpidos por Dios en el momento en que Él lo desee. Esta negación del principio de causalidad se convirtió en un artículo de fe para los aš'aríes. Estos teólogos en realidad negaron la causalidad en sentido general, sólo para absorber todas las

7 «Teoría de la causalidad en el Tahāfut de Averroes», en Actas del Primer Congreso de Estudios Árabes e Islámicos, Madrid, 1964, p. 115. 
causas secundarias en la Causa Primera y sólo por este ocasionalismo riguroso pensaron salvar la omnipotencia de Dios.

A Averroes no se le escapó esta inquietud apologética en la elaboración de una filosofía de la naturaleza:

Los atomistas musulmanes que niegan la potencia humana y abolen por eso la sabiduría práctica, el libre arbitrio y todas las fuerzas productoras, sostienen estas tesis no porque las hayan descubierto por propia reflexión, sino porque ven ahí el medio de defender principios que habían admitido previamente. ${ }^{8}$

Frente a estos teólogos, para quienes el principio mismo de una filosofía autónoma es ignorado, los filósofos musulmanes sustentaron una rigurosa doctrina de la causalidad y consideraron que todo fenómeno de la naturaleza es el efecto de un conjunto de causas, las cuales una vez manifestadas, producen necesariamente el efecto. Consideraron la naturaleza como el principio del cambio y la física como la ciencia que estudia las cosas que cambian. «La naturaleza - dice Averroes- es principio y causa porque gracias a ella se mueve y reposa aquello en lo que se encuentra primariamente y por esencia».?

Los cuerpos no están compuestos de átomos, sino que son continuos puesto que todos están compuestos de materia y forma. De igual modo, espacio y tiempo son continuos, y un punto del espacio o un instante del tiempo no son más que un aspecto de una realidad continua abstraída por la mente, que carece de existencia objetiva independiente. De aquí la insistencia de Averroes en subrayar la existencia meramente intencional del punto y del instante:

Así como el punto es el que hace la línea y la delimita y gracias a él el continuo está dotado de partes, así el instante es el que hace el tiempo y lo delimita. [...] El instante es el límite común al pasado y al futuro. Por eso el tiempo pertenece a lo continuo y sus extremos son dos instantes. ${ }^{10}$

Aunque los filósofos musulmanes no se oponen a la acción de la Voluntad divina en la naturaleza, basan su teoría en una cadena de causa y efecto que conecta todos los acontecimientos no directamente, sino a través de esa cadena con la Causa Primera. La intención principal de Algacel y de los mutakallimūn aš'aries había sido preservar la contingencia al mismo tiempo que la dependencia del orden natural. Aunque opuestos a los teólogos en estas cuestiones, también los filósofos pusieron de relieve la dependencia ontológica de la naturaleza con respecto al Ser Necesario. Pero en su opinión «cuando se dice que Dios es la causa de todo, se quiere decir que es la causa lejana». ${ }^{11}$ La naturaleza para

8 Compendio de Metafísica, trad. de Carlos Quirós, Madrid, 1919, pp. 139-140.

9 Epitome de Física, trad. de Josep Puig, Madrid, 1987, CSIC-IHAC, p. 118.

10 Ibid., pp. 164-165.

11 Tahāfut al-Tahāfut, ed. cit., p. 90. 
ellos es contingente en tanto depende de Dios para obtener la existencia. Sin embargo tiene realidad propia y se puede legítimamente hablar de la naturaleza como de algo separado de la Voluntad divina.

En abierta oposición al atomismo de la escuela as sarí, dirige Averroes una crítica enérgica a al-Ŷuwaynì (maestro de Algacel) acusándolo de ignorar la necesidad de lo que existe. Esto lo llevará, como veremos después, a combatir la doctrina de Avicena del ser. Para el filósofo cordobés no sólo el ser necesario incausado, Dios, es necesario por sí mismo; también lo es todo el mundo causado en tanto que está sometido a un principio causal a través de los géneros, especies e individuos. Desde siempre el mundo creado es contingente y posible, hasta que Dios le da el ser y con él la necesidad. En el ser real actual no hay contingencia ontológica posible; las cosas si existen, son necesarias porque incluyen en su ser presente la necesidad de ser propia de la causa. ${ }^{12} \mathrm{La}$ crítica de Averroes contra estos teólogos negadores de las causas segundas es enérgica, pues niegan la existencia de la naturaleza y de la verdad, y «destruyendo por completo la naturaleza de lo posible, se ven obligados a aceptar como consecuencia que lo posible es necesario y lo necesario posible». ${ }^{13}$

Para Averroes, que en este punto se distancia de Avicena, la existencia de la naturaleza y sus causas es evidente:

Que las cosas engendradas tienen cuatro causas, eficiente, materia, forma y fin es algo evidente per se. Igualmente es sabido por sí mismo que estas causas son necesarias para la existencia de los efectos; sobre todo aquellas que forman parte del efecto, $\mathrm{y}$ entiendo por esto lo que algunos llaman materia y otros condición y de otra parte lo que algunos llaman forma y otros cualidad intrínseca. ${ }^{14}$

Todo cuanto está sujeto al proceso natural procede de otro semejante a él, está compuesto de materia y forma y es en acto un individuo concreto en el que se da además del elemento formal y material, el eficiente y final. Admitida la existencia de las cuatro causas, Averroes sostiene que en realidad « lo que el agente produce no es más que el compuesto de materia y forma mediante la producción del cambio en la materia, transformándola de tal manera que se actualice formalmente lo que era en potencia». ${ }^{15} \mathrm{~A}$ esto se reduce la operación de la causa. Es evidente que un agente así concebido no se puede identificar con una sola causa eficiente, como pensaban los mutakallimün negadores de las causas segundas. Éstos creían que todos los tipos de acción suponen una creación ex-nihilo, mientras que lo que el verdadero agente opera es el paso de la potencia al acto. La relación potencia -acto es, pues, la condición para que se den los cambios que observamos en los entes reales concretos. Aquellos teólogos por el contrario, como sostienen que Dios es causa única de todo cuanto comienza, cambia u ocurre, conciben las acciones a la manera de accidentes cualitativos que

12 Compendio de Metafísica, ed. cit., pp. 151-152.

13 Ibid., pp. 138-139.

14 Tahäfut al-Tahäfut, ed. cit., p. 319.

15 L'Encyclopédie de l'Islam, 2." ed., tomo III, p. 943. 
se dan o asientan en un substrato. Tal afirmación a juicio de Averroes está desprovista de todo fundamento:

La opinión que niega las causas de un modo total es contraria a la naturaleza humana y la que las niega en el mundo, cierra el camino para afirmar la existencia de una causa eficiente en el mundo invisible, pues no se pueden alcanzar las causas invisibles sino partiendo de las causa visibles. Así pues los ašaríes carecen de camino alguno para conocer a Dios Altísimo, en tanto se niegan a reconocer que no hay efecto $\sin$ una causa. Siendo así, la creencia unánime de los musulmanes acerca de que no existe otro creador que Dios Glorioso, no puede significar la negación absoluta de la causa eficiente en el mundo visible, pues de la existencia de ésta aquí deducimos la del agente en el mundo invisible. ${ }^{16}$

Es verdad que en opinión de Averroes son más evidentes las cosas que sus causas. Pero también es verdad que la existencia de la cosa implica la de las cuatro causas por las cuales subsiste:

En esta ciencia -física - y en algunas de las propiedades de la cosa, se puede ofrecer a la vez la causa y la existencia, pero es en el menor número de los casos [...] y por ello la mayor parte de lo que se da en esta ciencia tiene que comprobarse mediante el sentido para luego buscar el conocimiento de sus causas. ${ }^{17}$

Es en el fenómeno del cambio donde se manifiesta una causa eficiente. La experiencia nos enseña que los entes finitos son causa unos de otros, y en este cambio en un sujeto, en la generación sustancial, va a insistir Averroes. El pensador musulmán subraya con fuerza que una cosa no se engendra de cualquier otra y mucho menos de nada en absoluto. Lo que se manifiesta es que «existe una relación esencial entre lo engendrado y aquello de lo que se engendra». ${ }^{18}$ Es cierto que no todos los cambios son iguales, pero «en todos los tipos de cambio existe una proporcionalidad y los términos de todo cambio guardan una relación, de lo contrario la casualidad regiría el mundo». ${ }^{19}$ Esta insistencia de Averroes en la generación sustancial se explica por la negación de la generación de unas cosas en otras por parte de los mutakallimūn $n$ ašaries. Algunos de estos teólogos y Algacel admiten que hay cosas que son condición de otras y que entre la condición y lo condicionado no cabe separación posible, aunque aquélla no sea causa de éste, ${ }^{20}$ pero:

16 Tahäfut al-Tahāfut, ed. cit., pp. 231-232.

17 Epitome de Física, ed. cit., p. 111.

18 Ibid., p. 106, p. 52.

19 Ibid., p. 52.

20 Cf. L. E. Goodman, «Did al-GhazāTi deny causality?», art. cit., pp. 84-87. En su opinión, Algacel sí admitió una auténtica causalidad en la naturaleza. Lo que rechaza de la doctrina de los filósofos es su afirmación de una relación necesaria entre causa y efecto. La conexión causa-efecto existe para el teólogo persa, pero no es una conexión necesaria y suficiente, sino sólo un rasgo del orden establecido por Dios en la naturaleza. 
Los fenómenos, que se suceden sin que uno sea condición del otro, cabe, a nuestro juicio, que se desligue el uno del enlace con el otro a que va anejo. Más aún: su enlace estriba sólo en que juzgamos por lo que vemos habitualmente. Así, la combustión del algodón en contacto con el fuego y el enfriamiento de la mano al tocar la nieve. Todos esos fenómenos acaecen enlazados así constantemente porque ése es el curso de la ley impuesta por Dios. ${ }^{21}$

Frente a la posibilidad de la generación sustancial, Algacel afirma que todos los seres, lo mismo sustancias que accidentes, son temporales y que Dios es el único agente de su creación «de modo que la imposibilidad o absurdo de la generación física de los fenómenos naturales se funda en la tesis de la universal extensión de la divina omnipotencia, puesto que de lo contrario quedaría anulada la omnipotencia, lo cual es absurdo, además de implicar incapacidad de Dios». ${ }^{22}$ Este pasaje deja muy claro que no son razones de orden natural en contra de la causalidad de la naturaleza las que convencen a Algacel, sino la doctrina de la omnipotencia divina. En realidad, toda la cuestión diez y siete de su Tahäfut al-Faläsifa va orientada a buscar un espacio libre en el que puedan tener lugar los milagros y a dejar bien sentado que Dios es agente de todo. El teólogo persa reconoce que los filósofos admiten los milagros:

Los milagros - dice Averroes - son principios confirmatorios de las leyes y lo que debe decirse de la Ley es que sus principios trascienden el entendimiento humano, por lo cual deben ser admitidos aun ignorando sus causas. Por eso no encontramos que ninguno de los antiguos filósofos haya tratado de los milagros a pesar de haberse éstos realizado. ${ }^{23}$

Sin embargo Algacel habla de milagros de más categoría que los admitidos por los filósofos, como convertir un bastón en serpiente o resucitar un muerto. Son los milagros relacionados con la vida, el conocimiento y la actividad sobre la materia inerte los que verdaderamente preocuparon a Algacel. En su opinión, hay que observar estos milagros como posibilidades divinas que, aunque no se pueden observar, no se pueden negar. Basa su afirmación en la susceptibilidad de la materia de recibir cualquier forma. Si se admite que unas cosas proceden de otras por causalidad y que la relación entre la causa y el efecto es necesaria como sostenían los filósofos, entonces dicha relación causal no deja lugar para el milagro. Por eso Algacel defiende la teoría de la causalidad de los aš́aríes donde el milagro entra cómodamente. No obstante, conviene insistir en que Algacel no fue un mutakallim más. Sus argumentaciones, como podemos comprobar, tienen consistencia lógica. Además, aunque mantuvo las grandes tesis ašaríes de la negación de las causas segundas, la predeterminación al mal y el voluntarismo divino, no las apoyó en el atomismo de la escuela. No sólo rechazó explícitamente la discontinuidad admitida por aquellos teólogos del

21 El Justo Medio en la Creencia, trad. de M. Asín Palacios, Madrid, 1929, p. 156.

22 Ibid., pp. 159-160.

23 Tahăfut al-Tahāfut, ed. cit., p. 327. 
tiempo, del espacio y de la materia, sino que también afirmó explícitamente una conexión causal entre los fenómenos, no necesaria ni suficiente, es cierto (puesto que Dios o algún intermediario intervienen en el curso habitual de los fenómenos), pero causalidad al fin y al cabo. Por otra parte, incluso el ocasionalismo moderado de al-A $\tilde{s}^{\prime} a r \bar{l}$ y su escuela es rechazado por Algacel. A su juicio, no asignaba una consistencia suficiente a la acción creadora de Dios ni una estabilidad suficiente a la naturaleza, que al igual que los filósofos, contemplaba como la expresión de la sabiduría divina. ${ }^{24}$

Para lo único que recurrió al atomismo, fue para explicar su teoría de los accidentes:

Cuando decimos que la sangre se convierte en semen, lo que con ello queremos significar es que una misma materia se despoja de una forma y se reviste de otra, pero permaneciendo la materia y sucediéndose en ella ambas formas. ${ }^{25}$

Aunque Algacel admite que las formas al emanar no descienden sobre cualquier sujeto sino sólo sobre aquel convenientemente preparado, concluye que el hecho de que por ejemplo, observemos que algunos animales como los gusanos se engendren de la tierra y no por acoplamiento, debe conducirnos a admitir que «se resisten a toda norma los principios de las disposiciones». ${ }^{26}$ Admitido esto, la posibilidad del milagro deriva inmediatamente. Con respecto a la combustión del algodón en contacto con el fuego, sólo se percibe el resultado, pero no la actividad del fuego; «la observación sólo demuestra que la combustión se produce con ocasión del fuego, no por el fuego.[...]. En cuanto al fuego, es un ser inorgánico sin actividad alguna». ${ }^{27}$ Además «nosctros admitimos que entre ambos haya contacto sin que se produzca la combustión, así como que el algodón se reduzca a cenizas por combustión sin que el fuego lo toque». ${ }^{28}$ Estos pasajes demuestran claramente que el que una cosa acompañe a otra no prueba que sea causa de otra, que los seres inorgánicos no tienen actividad y que aun admitiendo que el fuego queme, el milagro entra de igual modo en esta doctrina de la causalidad. ${ }^{29}$

Averroes no pudo admitir estas conclusiones tan contrarias a la experiencia. La causalidad de las causas segundas es tan amplia como el ámbito de los seres. Argumentar

24 Es plausible sostener que Algacel rechazó el ocasionalismo de estos teólogos no tanto por razones lógicas, sino teológicas. En su opinión la Voluntad divina es arbitraria pero no caprichosa como parecía desprenderse de la doctrina del voluntarismo divino sostenida por aquellos teólogos. Cf. L.E. Goodman, «Did al-Ghazāil deny causality?», art. cit., pp. 106-107.

25 Tahäfut al-Tahäfut, ed. cit., p. 327.

26 Ibid., p. 328.

27 Ibid., p. 317.

28 Ibid., 323.

29 En opinión del P. Luciano Rubio las admisiones de Algacel con respecto a la causalidad de los seres naturales no son concesiones verdaderas. Se trata de concesiones dialécticas, y por eso en lugar del presente «admitimos» prefiere la traducción «admitamos». En caso contrario existiría una contradicción demasiado grave en la exposición de Algacel. Cf. El ocasionalismo de los teólogos especulativos del Islam, Salamanca, Ediciones Escurialenses, 1987, p. 191. No es ésta la opinión de L. E. Goodman, que como ya hemos subrayado sí admitió una concesión verdadera por parte de Algacel en relación a la causalidad en la naturaleza. Cf. «Did al-Ghazāil deny causality?», art. cit., pp. 84-107. 
que lo inorgánico por carecer de vida no puede tener actividad es insostenible para el pensador musulmán, que percibe su actividad como el paso de una cosa desde la existencia en potencia a la existencia en acto. Si únicamente se admite la mera sucesión entre las cosas, no es posible hablar de relaciones esenciales entre ellas, ni por tanto de generación ni de causalidad. La generación de cualquier sustancia natural es por su misma esencia natural, lo que quiere decir causal y no arbitraria. Ni siquiera el hecho subrayado por Algacel de los animales que se engendran de la tierra destruye su convicción. Si de la tierra surgen seres vivos, no es por azar; en estos casos la tierra representa el papel seminal. ${ }^{30}$

Pese a su riguroso sentido de la causalidad física, Averroes admite la existencia de causas accidentales. Reconoce con Aristóteles que aunque en su conjunto el mundo es necesario, algunas cosas ocurren espontáneamente y por eso su agente es la casualidad. Frente a la concepción determinista de Avicena de la aniyya universal y eterna reconoce que «la casualidad pertenece a la clase de causa eficiente pero por accidente, no por esencia». ${ }^{31}$ La relación causa-efecto siempre es necesaria, pero una causa puede interferir un proceso causal natural, existiendo entonces en otra cosa por accidente la misma causa que existía en algo por esencia. Por ello replicará a Algacel:

No puede afirmarse de manera decisiva que al acercarse el fuego a un cuerpo sensible el fuego obre irremisiblemente, porque nada tiene de inverosímil que haya un ser que diga al cuerpo sensible una relación que impida la otra relación productora del fuego. ${ }^{32}$

Por supuesto esto no implica que el fuego pierda su cualidad de quemar. Éste sigue siendo fuego y definiéndose como tal. De todo lo dicho, no cabe ninguna duda de que los seres operan unos en otros y que «en su actividad no se bastan a sí mismos, sino que necesitan de un agente exterior cuya operación es condición para que operen y con mayor razón para que existan». ${ }^{33}$

El fenómeno de la generación sustancial conduce a la necesidad de distinguir en el cuerpo generado la materia y la forma, correspondientes con los dos momentos metafísicos de la potencia y el acto. En la realidad, es decir en el ente concreto, son inseparables, aunque en opinión de Averroes teóricamente tiene primacía la forma sobre la materia, en tanto que es ella la que nos da a concebir la naturaleza de las cosas. ${ }^{34}$ La materia se encuentra individualizada en el concreto, lo que conduce fácilmente a la materia prima, la más conocida de las causas, pura posibilidad. ${ }^{35}$ En cuanto a la forma, intrínseca a la materia, es

30 Epitome de Física, ed. cit., p. 125.

31 Ibid., p. 125.

32 Tahäfut al- Tahāfut, ed. cit., p. 319.

33 Ibid., p. 320.

34 Cf. Compendio de Metafisica, ed. cit., p. 84.

35 Conviene distinguir entre potencia y posibilidad en tanto que ésta se opone a la necesidad y aquélla al acto, lo que puede llegar a ser pero aún no es. La materia está en potencia y posee posibilidad. Pero además es sustancia. Contiene así las dos consideraciones aristotélicas de potencialidad y sustancialidad. Cf. R. Ramón Guerrero, «Sobre el concepto de materia en Averroes», en Al Encuentro de Averroes, ed. de A. Martínez Lorca, Madrid, Editorial Trotta, 1993, pp. 83-87. 
la que procede del agente. Con respecto a la finalidad, la última de las cuatro causas, Averroes no vacila en afirmar que existe, pues se ve que todo lo que hace la naturaleza lo hace con vistas a un fin. Al igual que para Aristóteles, la finalidad ocupa un lugar preeminente dentro de su sistema, tanto más cuanto que la teología islámica había optado precisamente por el atomismo, que, como hemos visto, supuso en el Islam una negación de todo tipo de causalidad, no sólo la final:

Si no fuera cierto que la Naturaleza actúa con un determinado fin, entonces lo que ocurre por su causa ocurriría excepcionalmente, no regularmente. En otras palabras, desaparecerían las demás causas, porque las tres causas son consecuencia necesaria de la finalidad y su existencia resulta de ella, de modo que la necesidad en las causas restantes se remonta a la finalidad, no a la materia prima como pensaba la mayoría de los antiguos filósofos de la naturaleza. ${ }^{36}$

Es imposible e inútil como ya señaló Aristóteles, pretender explicar todo el mundo de los entes naturales partiendo de una sola causa. Las cuatro confluyen en la realidad concreta, y cada una de ellas posee en su género una causa primera incausada. Éstas se remontan a su vez a una sola causa primera, Dios, Causa de las causas, Forma de las formas, Motor de los motores y Fin hacia el que está ordenada toda la creación. ${ }^{37}$ En Dios la causa es única; fuera de Él se va diversificando hasta llegar a la actualización de la materia.

\section{LA CAUSALIDAD DEL HOMBRE}

Aunque los teólogos musulmanes en su mayor parte fueron ocasionalistas metafísicos y epistemológicos, no podemos afirmar que rechazaron el principio de causalidad. Rechazarlo significaría afirmar que los acontecimientos tienen lugar sin ninguna causa eficiente y estos teólogos nunca dijeron eso. Lo que afirmaron es que la única causa eficiente de todos los efectos es Dios y que por tanto las criaturas no pueden ser causa de nada.

El principio fundamental de la doctrina ašarí según el cual «en Dios coinciden exactamente los objetos a que alcanza su conocimiento, los objetos que quiere su voluntad y los objetos a que se extiende su poder de ejecución temporal», ${ }^{38}$ se oponía abiertamente al sistema de los filósofos que no exigía que el ente primero creara ninguna cosa por vía de libertad o elección, sino que exigía necesariamente la existencia de la Inteligencia Primera por la cual y a través de la cual, siempre por vía de necesidad, se expandía el flujo de la potencia creadora. Por esta razón todos los aš'aríes, y entre ellos Algacel, distinguieron entre causa eficiente y agente. Por otra parte; si Dios es creador y agente único de todo, si

36 Epitome de Física, ed. cit., p. 123.

37 Compendio de Metafísica, ed. cit., 196-197.

38 Cf. Fray Luciano Rubio, El ocasionalismo de los teólogos especulativos del Islam, ed. cit., p. 80. 
Dios lo conoce todo y todo lo que conoce lo quiere y todo lo que quiere lo ejecuta, no hay lugar para la intervención de las causas segundas. Este puro voluntarismo y este rechazo de la eficacia de las causas segundas condicionó toda su cosmología. Tras aplicar las nociones obtenidas en el campo cosmológico al campo antropológico, al que añadieron los conceptos de vida, potencia operativa y conocimiento, su antropología resulta íntimamente ligada a su cosmología.

En realidad, los teólogos musulmanes nunca distinguieron bien los distintos aspectos de la causalidad. La razón estriba en que estos teólogos aplicaban espontáneamente el principio de causalidad por considerarlo evidente sin tener conciencia explícita del mismo, viéndose obligados a hablar mucho de la causalidad de Dios y de las criaturas por problemas religiosos y morales, especialmente del hombre. ${ }^{39}$ Ahora bien, si se supone que Dios es causa única de todo, el hombre no es capaz de obrar o no obrar, de obrar esto y no aquello. Sin embargo en el Corán hay muchos pasajes que presentan al hombre dueño de sus propias acciones, con capacidad para obrar el bien y evitar el mal. También es verdad que hay otros muchos que subrayan la absoluta trascendencia y omnipotencia de Dios y su predeterminación de todo cuanto ocurre.

Es evidente que ante esta alternativa coránica, la solución a los problemas relacionados con la causalidad y a las objeciones basadas en el Corán es una cuestión de exégesis. De hecho, tanto los teólogos que anteponen el dato revelado a cualquier otra razón y para quienes el problema de la causalidad arranca del Corán mismo, como los filósofos, para quienes este problema arranca de una toma de posición filosófica, alegan textos coránicos y hacen exégesis de los mismos para justificar sus doctrinas.

Los teólogos musulmanes (tanto mu 'tázilies como aš'aries) fueron siempre reacios a la terminología de la causalidad derivada de la filosofía aristotélica. Temían que esta terminología, incluso respectos a Dios, implicase necesariamente la producción del efecto y por consiguiente la producción o simple emanación eterna del mundo respecto de Dios.

Por eso, cuando hablan de la causa eficiente, prefieren hablar de agente y acción o de productor y producido en lugar de causa y efecto, «porque la potencia operativa del Eterno no es «causa» ni «canal» de lo que cae bajo el poder del Eterno ni lo exige necesariamente»..$^{40}$ Averroes reconoce que «el término agente no se dice unívocamente de Dios y de las demás causas», puesto que todas las causas diferentes a Dios no existen junto con sus efectos más que por Dios, «pero las causas obran, no solamente porque Dios se sirva de ellas como un instrumento, sino porque Él las crea como causas». ${ }^{41}$

A diferencia de los agentes naturales cuya actividad consiste en educir de la potencia al acto, Averroes distingue en el hombre la actividad que procede del entendimiento y de la voluntad. Existe una auténtica causalidad en ambos pensadores, pero a diferencia de los

39 Ibid., pp. 15-17.

40 Al-Baquillānī, Kitāb Al-Tamhīd, ed. cit., p. 77; cit. en Fray Luciano Rubio, El ocasionalismo de los .teólogos especulativos del Islam, ed. cit., p. 119.

41 L'Encyclopédie de l'Islam, 2.․․ ed,, tomo III, p. 939. 
primeros, que operan siempre y necesariamente un único tipo de acción, los agentes voluntarios son capaces de actuar contrariamente, pues «sólo en los seres animados se da la virtud de poder dirigir alternativamente el cambio hacia cada uno de los dos contrarios bajo la acción de una especial motivación: el deseo»». ${ }^{42}$ Es evidente que por esta capacidad de elegir entre dos cosas opuestas el hombre es libre y responsable de sus propias acciones. El siguiente pasaje del Tahāfut no deja ninguna duda de que este era el auténtico pensamiento de Averroes, además de dejar sentado que Dios es Causa de las causas y por tanto único creador de todo cuanto existe:

Según los filósofos el mundo se parece a una ciudad; como la ciudad se constituye por un sólo jefe primero que domina a muchos otros jefes, el mundo lo es igualmente. [...] Los filósofos además han descubierto que aquel que da a los seres separados su fin es el mismo que les confiere su existencia, pues en este tipo de seres la forma y el fin son idénticos; y así aquel que da el fin es quien da la forma; luego el que da la forma es el agente. Así pues, parece que el Principio Primero es el principio de todos estos principios en tanto que es el Agente, la Forma y su Fin. En cuanto a su relación con los seres sensibles, en tanto que es Él quien les da su unicidad y que ésta es causa de la existencia de la multiplicidad de la cual constituye un lazo, El será principio en tanto que Agente, Forma y Fin. Todos buscan pues su fin y se mueven hacia él, cada uno con un movimiento propio de su razón de ser, natural para todos, voluntario para el hombre; $y$ por esto el hombre es entre ellos el único responsable y el único confidente. ${ }^{43}$

Algacel en defensa de su tesis de que Dios quiere todo lo que ocurre sin que nada suceda en contra de su voluntad, había acusado a los filósofos de sostener que las cosas proceden de los principios de una manera necesaria y natural, no por vía de reflexión y elección. Contra esto responde Averroes:

Eso no lo ha dicho ningún filósofo de cuenta. Al contrario, para los filósofos todo lo que está dotado de ciencia obra por elección; si bien por la excelencia que reina en el más allá, de los contrarios siempre se elige el mejor. ${ }^{44}$

La voluntad de Dios no puede concebirse a partir de la nuestra. La facultad que tiene el hombre de elegir entre dos cosas opuestas supone al mismo tiempo un deseo de algo y el situarse en el terreno de la posibilidad y no de la necesidad. Esta característica de la voluntad humana es evidente que no puede darse en la divina, como tampoco el carecer de nada cuanto se quiere, cosa que sí nos sucede a nosotros. Por eso Averroes responde a Algacel

42 Tahäfut al-Tahāfut, ed. cit., p. 125.

43 Ibid., pp. 159-160. El subrayado es mío.

44 Ibid., p. 322. 
que los filósofos no niegan la Voluntad al Creador Glorioso, pero mucho menos le atribuyen la voluntad humana. ${ }^{45}$

El término voluntad expresa el modo de acción de un ser absolutamente trascendente. Por eso no vio Averroes ningún inconveniente en que un creador tal produjera una multiplicidad de seres como efecto de su acto, rechazando así el principio que está en la base de las doctrinas emanatistas de que de lo Uno sólo deriva lo uno. ${ }^{46}$

En cuanto a los teólogos musulmanes, todos diferenciaron la acción de Dios de la acción del hombre diciendo que aquélla es acción de creación y la humana de adquisición. La cuestión de la adquisición fue ampliamente tratada por todos ellos, aunque la entendieron de maneras muy diferentes. En verdad, salvo los $m u^{6}$ tazilies, que admitieron una auténtica causalidad en el hombre, el resto de los teólogos la redujeron a un simulacro de causalidad. En su opinión, si los hombres ejecutaran libremente sus acciones, el poder de Dios quedaría dismimuido. No obstante, todos dieron por supuesto que el hombre tiene adquisición, su campo de acción, y la definieron como sigue:

El sentido de la adquisición es que la cosa ocurre mediante una potencia producida por Dios. Por lo tanto, lo obrado será adquisición de aquel a partir del cual (lo obrado) ocurra mediante su potencia. ${ }^{47}$

Esta definición parece expresar que el hombre es agente de su adquisición, pero esto lo negaron expresamente. Lo que afirmaron es que Dios ha dotado al hombre de una potencia operativa, en virtud de la cual puede adquirir o apropiarse las obras que Dios, único agente, crea para él.

Una de las pruebas racionales más utilizadas por los aš'aries en defensa de que Dios es el agente de las obras del hombre, consistió en distinguir entre movimientos necesarios y no necesarios. Consideraron a los segundos como acciones adquiridas en las que interviene de alguna manera el hombre mediante la potencia recibida de Dios, pero negaron que el hombre fuera su agente:

\begin{abstract}
Observamos en nosotros una diferencia entre ambos estados (movimiento por elección y movimiento convulsivo) expresando tal diferencia por la palabra poder. Llegamos a conocer que lo que sucede con los dos miembros (de la división) ambos posibles, es la creación por Dios del movimiento con poder (en nosotros) para realizarlo en un caso (movimiento libre) y sin poder para realizarlo en el otro (movimiento convulsivo). ${ }^{48}$
\end{abstract}

45 Ibid., p. 264. Dios es la causa del universo y esta causa es idéntica a su acto, no engendrado y eterno, pero querido. Cf. R. Hayoun y Alain de Libera, Averroès et l'averroïsme, París, Presses universitaires de France, 1991, pp. 28-29.

46 Tahāfut al-Tahāfut, ed. cit., p. 107.

47 Al-Ašañī, Maqālat al- Islāmiȳinn, ed. Cairo, 1950, II, p. 199; cit. en Fray Luciano Rubio, El ocasionalismo de los teólogos especulativos del Islam, ed. cit., p. 91.

48 Tahäfut al-Tahäfut, ed. cit., p. 330. 
Según este pasaje es evidente que la intervención del hombre en los movimientos de adquisición no consiste en producir la acción, puesto que esto se reserva a Dios. El campo de acción del hombre es francamente pequeño. Parece que con tal potencia sólo puede aceptar dicha acción. Aunque Algacel habla de dos potencias, una divina y otra humana, ésta no influye para nada en la producción del objeto. A lo más-que llega la potencia del hombre es a distinguir los movimientos adquiridos (libres) de los necesarios. El hombre se da cuenta en esas acciones de que tiene potencia para ellas, pero su intento lo crea Dios y si deja de obrar es porque Dios ha dejado de crear nuestro intento. Por eso afirma Algacel que «la potencialidad es de Dios y el provecho del hombre». ${ }^{49}$

Aún se estrecha más el campo de la libertad del hombre si tenemos en cuenta que la potencia es potencia para obrar algo y no para omitirlo:

Es de necesidad que sea condición de la potencia del hombre que al darse su existencia se dé la existencia del objeto para el cual es potencia. Dado que esto es así es imposible que el hombre pueda obrar una cosa y su opuesto, porque si pudiera obrar ambas cosas sería de necesidad la existencia de ambas y eso es absurdo. ${ }^{50}$

Ya hemos apuntado que los ašaríes conciben las acciones a modo de accidentes cualitativos que se asientan en un substrato. Esta potencia es, pues, un accidente transeúnte (como todos los accidentes), simultáneo al acto (puesto que si no, sería independiente de Dios) y sólo potencia para obrar la obra y no para omitirla. Además tampoco es potencia para hacer dos cosas distintas. Efectuada la obra para la cual es potencia, ésta desaparece y para hacer otra obra debe ser creada de nuevo por Dios.

Es evidente que una potencia tal no deja espacio para la libertad, aunque estos teólogos afirmaran lo contrario. Esta concepción de la causalidad supone a juicio de Averroes la destrucción de la vida misma del hombre. Sus adversarios no sólo niegan las acciones operadas por los objetos naturales alegando que lo que no es vivo no actúa de ningún modo; también «niegan las acciones de los seres del mundo visible afirmando que parecen proceder del viviente en el mundo sensible, cuando en realidad su verdadero agente reside en el mundo invisible, lo que implica la negación de la vida en el mundo sensible, ya que aquí sólo se puede probar la vida partiendo de las acciones. ${ }^{51}$

49 «Libro de los cuarenta principios de la religión», en M. Campanini, L' intelligenza della fede. Filosofia e religioni in Averroé e nell' averroismo, Bérgamo, Pierluigi, Lubrina editore, 1989, p. 80.

50 Al-Ašs'ari, Kitäb al-Luma', trad. Richard J. McCarthy, S. J., en The Theology of al-A s's ari, Beirut, 1953, n. 126; cit. en Fray Luciano Rubio, El ocasaionalismo de los teólogos especulativos del Islam, ed. cit., p. 99.

51 Tahāfut al-Tahāfut, ed. cit., p. 318. 


\section{EL CONOCIMIENTO}

La negación de las causas segundas en defensa de la omnipotencia divina había llevado a los mutakallimūn as'saríes y a Algacel a negar toda entidad ontológica al mundo creado. Cuanto sucede es así porque Dios lo quiere. Aquello que Dios quiere no tiene ninguna naturaleza prefijada y determinada, de modo que no existe nada que no se reduzca a su arbitraria voluntad: «todas las operaciones de Dios le son contingentes sin que de ninguna de ellas se predique la necesidad». 52 Todas las cosas, por consiguiente, son posibles. Los universales son simples nombres carentes de realidad. Cualquier cosa puede ser diferente de lo que es y su posibilidad no demuestra la imposibilidad de su contraria. Los sentidos perciben una regularidad en los acontecimientos, pero no perciben ninguna interacción causal entre ellos. Su secuencia regular sólo se debe a la costumbre de Dios, única causa. No obstante, «la persistencia de la costumbre una vez tras otra consolida en nuestro entendimiento de una manera ineludible la creencia de que tales cosas posibles vayan por el cauce de la costumbre tradicional». ${ }^{53} \mathrm{Si}$ Dios rompe la costumbre con un milagro, dejará de crear en el hombre el conocimiento de esos posibles.

Es obvio que las consecuencias metafísicas y epistemológicas del ocasionalismo de estos teólogos imposibilitan alcanzar una ciencia de valor permanente y universal. Si negásemos la causalidad - dice Averroes- el mundo carecería de orden y de fin y no podríamos conocer a Dios. En su opinión no se puede deducir del azar la existencia de un Primer Motor ordenador y además haría inexplicable el orden que apreciamos y que hace posible el conocimiento humano. ${ }^{54}$ Para Averroes es absurda la opinión de que cualquier ser puede ser diferente de lo que es. El ser real actual es necesario porque presenta la necesidad propia de la causa. Si no fuera así, no podríamos conocer ninguna cosa, ya que de lo no necesario no puede haber ni ciencia ni ignorancia sino sólo opinión. La estricta ciencia sólo es posible partiendo de las causas; sin ellas la filosofía sería imposible y tampoco podría haber un auténtico conocimiento teológico:

Debéis saber que cualquiera que niegue la influencia de las causas sobre sus efectos niega la sabiduría y la ciencia. Pues la ciencia consiste en conocer las cosas por sus causas y la sabiduría consiste en conocerlas por sus causas finales. ${ }^{55}$

El testimonio de los sentidos echa por tierra el argumento de que lo inorgánico por carecer de vida no puede tener ninguna actividad. Las cosas actúan unas en otras «porque es algo conocido por sí mismo que las cosas están dotadas de esencias y cualidades que exigen acciones propias para cada uno de los seres». ${ }^{56}$ Pero es que además las naturalezas

52 El Justo Medio en la Creencia, ed. cit., p. 245.

53 Tahäfut al-Tahāfut, ed. cit., p. 234.

54 Compendio de Metafísica, ed. cit., pp. 155-156.

55 Tahäfut al-Tahäfut, ed. cit., p. 109.

56 Ibid., p. 318. 
de las cosas se conocen por sus operaciones, «ya que por tales acciones se diversifican las esencias de las cosas y los nombres y las definiciones de éstas». ${ }^{57}$ Por lo tanto, suprimir las operaciones es suprimir las naturalezas y «suprimida la naturaleza del ser se sigue necesariamente la nada» ${ }^{58}$ Sin causas esenciales resulta incomprensible el ser. Así, hacer que las cosas dependan única y exclusivamente de Dios es acabar con nuestra ciencia de los seres naturales. Para Averroes el apoyo en la estructura ontológica de la realidad es imprescindible:

El conocimiento no lo es como ciencia de la idea general, sino el conocimiento de los seres concretos particulares de un modo general, propio del intelecto cuando abstrae la naturaleza única y común que reside particularmente en las cosas materiales. $^{59}$

Los ašaríes en general admitieron la validez del conocimiento evidente, pero el escepticismo, que no les abandonó nunca, les llevó a poner siempre más énfasis al estimar el valor de este conocimiento en el consenso de los hombres que en el valor intrínseco de la evidencia. El escepticismo de estos teólogos se refiere principalmente al testimonio de los sentidos externos, que a su juicio no perciben el influjo causal entre las cosas. Además, «¿cómo puede ser percibida mediante presenciación y aprehensión de los sentidos la realidad de aquello acerca de lo cual se dan tantas diferencias u opiniones? ${ }^{60}$ Frente a estos teólogos, Averroes no duda de que el hombre puede alcanzar la certeza:

Es evidente para todos que tenemos acceso a la verdad y que a menudo podemos alcanzarla. Nuestro deseo de conocer la verdad también lo prueba, pues si fuese imposible alcanzarla nuestro deseo resultaría vano. Pero bien sabemos que nada de cuanto está apoyado en el fondo mismo de la criatura es vano. ${ }^{61}$

La adecuación entre la realidad ontológica y nuestra ciencia sobre dicha realidad permite que nuestro intelecto, como tal, no pueda equivocarse. $Y$ como entender no es otra cosa que percibir los seres en sus causas, «quien suprime las causas suprime también el entendimiento». ${ }^{62} \mathrm{La}$ definición para Averroes proporciona la mayor certeza posible ya que se dirige a expresar la esencia de las cosas. Si en las cosas no existiera algún elemento esenciạl, no cabría definición ni conocimiento alguno sobre ellas. ${ }^{63}$ Los mutakallimūn, al

\section{Ibidem.}

58 Ibidem.

59 Ibid., p. 65; Compendio de Metafisica, ed. cit., p. 95.

60 Al-Baquillānī, Kitāb al-Tamhīd, ed. cit., n. 78; cit. en Fray Luciano Rubio, El ocasionalismo de los teólogos especulativos del Islam, ed. cit., p. 110.

61 Tafsì kitāb Mă ba'd al tabi ' $a$, ed. Bouyges, a, com, 1. p. 61; cit. en M. Cruz Hernández, (Averroes) Vida, obra, pensamiento, influencia, Córdoba, Cajasur, 1986, p. 338.

62 Tahāfut al-Tahāfut, ed. cit., 319.

63 Compendio de Metafísica, ed. cit., p. 75. 
admitir que los opuestos tienen la misma posibilidad para existir y que la preferencia de uno de los dos opuestos se debe sólo a a la arbitraria voluntad de Dios, acaban con nuestro conocimiento de los seres naturales, «porque la ciencia cierta (y apodíctica) es el conocimiento de la cosa tal como es en la realidad». ${ }^{64}$ Como es evidente que no podemos pensar al mismo tiempo dos contrarios porque en el ser sólo cabe uno de ellos, «se impone como necesario preferir para la existencia a uno de los dos opuestos». ${ }^{65}$ Esto prueba que existe la naturaleza del ser.

Su concepción realista del conocimiento llevará a Averroes a criticar la división aviceniana del ser necesario por sí, posible por sí y necesario por otro. ${ }^{66} \mathrm{Si}$ el ser significa la existencia, no podemos dividirlo. La realidad es una. La existencia no se añade a la esencia al modo de un atributo accidental como pensaba Avicena.$^{67}$ Las dos nociones sólo pueden separarse en el pensamiento, pero no en los entes reales concretos.

Algacel, por negar que los seres tienen una naturaleza esencial, afirmó que todas las cosas son posibles, que pueden ocurrir o no, cuando para el pensador cordobés es evidente lo contrario:

Es evidente que todas las cosas no son posibles, pues no es posible que lo corruptible (por ejemplo), sea eterno [...] o que los colores lleguen a ser objeto del oído. Tales afirmaciones son en extremo perjudiciales a la ciencia humana. ${ }^{68}$

Nuestra ignorancia de las cosas no se debe como sostenía Algacel a que Dios no ha creado en nosotros el conocimiento sobre ellas. Se debe a que ignoramos su naturaleza. El conocimiento no es «algo que se pega al alma de la criatura» como sostenía al-Bāquillānīi, ${ }^{69}$ y con él todos los ašraries y Algacel, sino una operación privativa de la potencia racional humana, que consiste en «despojar de su forma a la materia concreta y concebirla aisladamente en su ser íntimo». ${ }^{70}$ Aristóteles había dicho que «lo verdadero es la convicción de que la cosa está en el entendimiento tal como es en realidad». De este argumento cree Averroes que se han servido los mutakallimün para negar la existencia de los universales. ${ }^{71}$ Frente al nominalismo de éstos, defiende su existencia, puesto que la ciencia tiene que ser inteligible y esta cualidad sólo la tiene el universal. Sólo las formas abstractas son universales; son las ideas generales desprovistas de materia que únicamente pueden existir separadas de ellas tras el acto de abstracción, la operación más natural, esencial y definitoria del hombre, que el ocasionalismo de los mutakallimūn y Algacel pretendían echar por tierra.

64 Tahäfut al-Tahäfut, ed. cit., p. 325.

65 Ibid., p. 326.

66 Ibid., p. 119.

67 Ibid., p. 179.

68 Compendio de Metafisica, ed. cit., p. 271.

69 Kitāb al-Tamhīd, ed. cit., n. 9; cit. en Fray Luciano Rubio, El ocasionalismo de los teólogos especulativos del Islam, ed. cit., p. 111.

70 Compendio de Metafísica, ed. cit., p. 95.

71 Ibid., p. 94. 


\section{LA CREACIÓN DEL MUNDO}

El problema de la causalidad no sólo es importante en sí mismo, sino apasionante, ya que lo que en el fondo se discute es la compatibilidad entre el dogma coránico de la creación $e x$-nihilo y el origen del mundo a partir de Dios mediante una causalidad que suponga una emanación necesaria, o al menos una creación eterna. Este problema, central en todo el pensamiento islámico, surge inevitablemente si se da por supuesto que de la causa dimana necesariamente el efecto y se sigue creyendo que Dios es causa única o por lo menos causa primera de todo cuanto existe.

Una vez probado mediante la contingencia del mundo que éste tiene un Artífice, los teólogos musulmanes afirmaron que se trataba de un ser dotado de voluntad y de poder de elección, ya que tenía que escoger un momento determinado con preferencia a los otros posibles en que ha de comenzar el mundo y una manera determinada de ser las cosas producidas con preferencia a otras posibles. Obtenida esta conclusión, los teólogos pasaron fácilmente a demostrar que Dios es sabio, poderoso y volente.

Algacel en su Tahāfut insiste en que sólo un concepto de creación en sentido islámico puede conducir a la existencia de un Dios que activamente interviene en determinar cómo, dónde y cuándo lo contingente tiene lugar. El Dios del que hablan Algacel y todos los mutakallimūn aš'aríes no está vinculado a su creación, ya que goza de libertad de elección. Por ello el enfrentamiento de estos teólogos que parten del dato revelado de la creación $e x$ nihilo con la corriente filosófica, que parte de un concepto aristotélico de Dios y del principio neoplatónico de que de lo Uno sólo puede originarse lo uno, era inevitable. ${ }^{72} \mathrm{En}$ opinión de los filósofos:

La realidad o verdad del principio de nuestro sistema es que el mundo superior y el mundo de la generación y corrupción no tienen comienzo y ambos en relación con el ente primero son como lo causado y la causa. ${ }^{73}$

Los teólogos musulmanes no podían aceptar esa ligazón necesaria entre uno y otro. Por eso la única solución que vieron ante este problema fue demostrar que el mundo tiene comienzo, que fue creado por Dios de la nada en un preciso instante temporal. Les espantaba la concepción filosófica de un universo eterno y producido por emanación con una materia eterna recibiendo siempre nuevas formas. Pero lo más grave para ellos era que parecían conceder a Dios un papel apenas subsidiario en ese universo maravillosamente organizado

72 Es difícil definir filosóficamente la idea de creación, tanto más cuanto que no aparece explícita en el Corán. Además, de la doctrina fundamental de la unicidad divina que confiere a Dios una trascendencia absoluta, se desprende claramente que nos está prohibido saber cómo ha sido creado el mundo. Cf. Roger Arnaldez, "La doctrine de la création dans le Tahäfut», en Aspects de la pensée musulmane, París, VrinReprise, 1987, pp. 99-101.

73 Al-Ŷuwain̄, Kitāb al-irs̄ād, trad. J. D. Luciani, París, 1938, p. 214; cit. en Fray Luciano Rubio, El ocasionalismo de los teólogos especulativos del Islam, ed. cit., p. 139. 
y determinado en el que creían. Una doctrina así no solamente era para estos teólogos incompatible con el Islam, sino también poco convincente desde el punto de vista filosófico.

Al refutar las objeciones de Algacel, Averroes formuló una crítica a los filósofos yendo más lejos que aquél. Reprochó a Avicena, no su definición del ser necesario por la ausencia de causa, sino la vía que utilizó para llegar a este ser. En su opinión podemos hablar de un ser necesario y sin causa no en virtud de una división del ser, sino tras un examen de los seres del mundo. Es así preciso apoyarse en la necesidad de la generación y la explicación causal de ésta. La existencia de Dios, Primer Motor, debe demostrarse por vía física y no metafísica como pensaba Avicena:

Resulta evidente que el ser existente tiene un agente creador. Por esto quien desee conocer la existencia de Dios con conocimiento exacto, debe necesariamente tratar de conocer la sustancia de las cosas para comprender así el origen real de creación de todos los seres, pues quien no conoce la sustancia de la cosa, tampoco conocerá la razón sustancial de su origen por creación. ${ }^{74}$

Es cierto que del Dios de Avicena no podemos afirmar que sea un auténtico creador, pero al Dios de Averroes legítimamente se le puede llamar así, en tanto que es un agente voluntario que actualiza las potencias que están en el mundo:

La providencia primera que existe en nosotros es la de Dios (sea bendito y ensalzado), quien es causa de todo lo que habita en la tierra. Todo bien puro que aquí exista procede de Él y es querido por su voluntad. ${ }^{75}$

No es cierta la acusación dirigida por Algacel a los filósofos de negar la creación divina. Éstos reconocen la voluntad creadora en el sentida de que sus acciones se originan de una ciencia y «todo lo que nace de una ciencia y de una sabiduría sale de la voluntad del agente y no de la necesidad natural». ${ }^{76}$ Lo característico de las acciones divinas es no tener principio, y puesto que el movimiento es la acción del agente y de la existencia del mundo se sigue el movimiento, el agente del movimiento es agente del mundo. Ambos serán pues para Averroes eternos. ${ }^{77} \mathrm{~A}$ su juicio es incompatible con el propio concepto coránico del carácter todopoderoso de Dios que Éste hubiese tenido que esperar para crear en el tiempo, ya que esta espera estaría condicionada por algo extrínseco y Dios quedaría determinado en sus acciones. Además, «dado un agente en posesión de todas las condiciones para obrar, no es posible que se retrase el efecto». Sí es posible disociar la voluntad de un agente libre y la producción del efecto, pero «en un agente libre su decisión de actuar y la acción o

74 Kašf 'an Manāhiyā, P. Manuel Alonso, Teología de Averroes, Madrid-Granada, 1947, p. 227.

75 Compendio de Metafísica, ed. cit., p. 269.

76 Tahäfut al-Tahäfut, ed. cit., p. 322.

77 Ibid., p. 37. 
producción del efecto van indisolublemente unidos». ${ }^{78}$ Sólo cabe concluir que la creación del mundo tuvo que ser eterna.

El argumento de Algacel a favor del comienzo temporal del mundo por una Voluntad Eterna es a juicio de Averroes sofístico y arrastra muchos absurdos. El teólogo persa no sólo observa como posible que el mundo se retrasase después de quererlo el agente, sino también después de haber decidido su acto. ${ }^{79}$

Al igual que Platón, los teólogos musulmanes establecieron un primer movimiento en el tiempo, por considerar esencial la causalidad entre los movimientos que se suceden e imposible prolongarlos hasta el infinito. Pero no pudieron escapar a la dificultad de que antes de ese primer movimiento, debería haber existido otro que lo produjera. Averroes se enfrenta a estos teólogos y se distancia de al-Fārābì y Avicena. El primer movimiento debe ser eterno porque su móvil no puede ser contingente. Su punto de partida sigue siendo el rechazo de una cadena infinita de causas y efectos, la imposibilidad de una cadena infinita de motores, que conduce a la necesidad de un Primer Motor Eterno. ${ }^{80}$

Al confundir lo esencial con lo accidental - dice Averroes- los mutakallimūn y Algacel juzgaron que era imposible lo que no es imposible; que las causas sean infinitas es, pues, imposible esencialmente y posible accidentalmente. ${ }^{81}$ No existe un infinito en acto. Precisamente por esto la naturaleza es finita y nuestro conocimiento de los seres naturales es posible. Los entes finitos son causa los unos de los otros y por esta razón no pueden remontarse al infinito sino que necesitan un principio. Ellos sólo son causa por accidente, no esencial, y la infinitud del proceso radica en la infinitud del motor eterno. Por eso Averroes rechaza los argumentos en favor de la infinitud sólo en el futuro y no en el pasado, ya que confunden la finitud de las cosas contingentes con la infinitud del proceso de generación, olvidando que «lo que tiene principio tiene un fin y lo que no tiene ningún fin no tiene principio».82

Averroes reconoce que Dios queda fuera del tiempo, pero la precedencia lógica y ontológica de Dios respecto del mundo, no tiene que ser trasladada a una prioridad temporal. Los que sostienen lo contrario «cuando se les interroga de qué manera la causa eficiente del tiempo puede ser anterior al tiempo, bajan la cabeza». ${ }^{83} \mathrm{El}$ mundo no comenzó a existir

$78 \quad$ Ibid., p. 3.

79 Algacel, que al igual que los filósofos no admite que la voluntad divina sea comparable a la humana, se sirve precisamente de este argumento para rechazar sus conclusiones. Que nosotros no podamos retrasar el efecto de nuestras acciones y decisiones no implica que Dios no pueda hacerlo. Cf. Oliver Leaman, Averroes and his Philosophy, Oxford, Clarendon Press, 1988, pp. 16-18. Cf Tahäfut al-Tahäfut, ed. cit., pp. 5-6.

80 Compendio de Metafisica, ed. cit., p. 188.

81 Ibid., p. 148.

82 Tahäfut al- Tahäfut, ed. cit., p. 11.

83 Compendio de Metafisica, ed. cit., p. 149. 
después de no haber existido. Además «no es propio del mundo estar en el tiempo. Más bien el tiempo es algo que surge con el ser del mundo» ${ }^{84}$

Debido a que la infinitud se predica en potencia, está vinculada a la materia prima, cuya característica es precisamente la potencialidad, la capacidad de convertirse en todas las cosas al poder ser actualizada mediante la recepción de las formas. Esta materia no tiene principio. Imprescindible en cualquier acto de producción o creación, es eterna y precede a todos los cambios. ${ }^{85}$ Averroes criticó a los neoplatónicos como al-Fārābī o Avicena por negar la entidad de la materia. Éste último afirmó que el acto de un autor, o bien se refiere al ser 0 al no ser en tanto no ser, o a los dos juntos, lo cual es imposible. El acto del autor no se refiere al ser en acto en tanto está en acto, ni al no ser en tanto que es no ser, sino al ser inacabado, afectado por el no ser, el ser en potencia. ${ }^{86}$ Toda creación, incluso la divina, hay que concebirla «como una educción de la cosa desde la existencia en potencia a la existencia en acto; y el aniquilamiento, por el contrario, como educción de la cosa desde el acto a la potencia. De esto se deduce que la posibilidad y la materia son inherentes a toda cosa producida». ${ }^{87} \mathrm{El}$ agente no opera la forma en la materia, sino de la materia, sujeto de posibilidad de todos los seres. Por eso Averroes rechaza la teoría de al-Fārābī y Avicena del «dador de formas», equivalente al Ángel creador de los ašaries que suponía la existencia de formas separadas y su recepción mediata en la materia. En opinión de Averroes:

El abuso de tal suposición conduce a los teólogos de las tres religiones hoy conocidas a considerar como posible que algo proceda de la nada, pues si fuera posible la creación de las formas, también lo sería la de la totalidad. Pues creyendo que el agente primero sólo opera por innovación y creación de la nada y pudiendo observarse entre las cosas de aquí abajo que las unas operan sobre las otras, los mutakallimūn de nuestra religión afirmàn que existe un agente único que actúa sobre todos los seres directa, inmediata y por tanto simultáneamente sobre la infinidad de ellos, opuestos y no contrarios. Por ello niegan que el fuego queme, que el agua refresque y que el pan alimente..$^{88}$

A la doctrina de las tres religiones reveladas según la cual Dios crea el mundo a partir de la nada, Averroes opone la doctrina de Aristóteles, según la cual las formas son increables:

84 «Eternidad y creación: Discurso sobre la manera de existencia del mundo», trad. ingl, B. S. Kogan, en Islamic Theology and Philosophy, ed. M. E. Marmura, Albany, Suny Press, 1984, p. 209.

85 Compendio de Metafísica, ed. cit., p. 84.

86 Tahāfut al-Tahäfut, ed. cit., p. 98.

87 Ibid., p. 78.

88 Comentario a los tratados «De Metaphysica» de Aristóteles, ed. Venecia, 1552, vol VII, com. 18, cit. en M. Cruz Hernández, (Averroes)..., op. cit., p. 152. 
El agente no inventa la forma creándola, porque si la crease, entonces se haría algo a partir de nada y por eso la forma en su opinión no tiene ni generación ni corrupción sino accidentalmente, a saber, por generación y corrupción del compuesto. ${ }^{89}$

Averroes hubiera podido salvar el dogma de la creación ex-nihilo identificando la «nada» con el substrato informe de la materia. Ahora bien, que no admitiera tal doctrina, no significa que se le pueda acusar de negar al mundo una causa y un creador. Tanto en el Tahäfut como en sus obras de creación original son numerosos los pasajes en los que Dios viene representado como «aquel que hace pasar el universo del no-ser al ser» ${ }^{90}$ y como «causa y principio del ser sensible». ${ }^{91}$ Dios es causa del mundo, pero «el mundo no es propiamente ni creado ni eterno, porque lo creado es por necesidad corruptible, mientras que lo eterno no tiene ninguna causa que lo determine».92 Aunque Dios produce el mundo desde la eternidad, esto no quita para que sea ontológicamente inferior a Dios y «creado», en tanto que su causa es externa y necesita de un agente que lo pase de la potencia al acto. El mundo no es por lo tanto para Averroes «eterno por sí mismo» ni existe sin estar movido por otro. De aquí que le convenga más la producción que la eternidad, y aclara el pensador musulmán:

Si los filósofos llaman al mundo eterno es para prevenir que se lo crea originado de la nada y creado en el tiempo después de un período de inexistencia.. ${ }^{93}$

Dios ordena, jerarquiza y vuelve inteligible un mundo qủe existe ya al menos en cuanto potencialidad indiferenciada. Más que concebir a Dios como causa de todos los seres, Averroes lo concibe como causa que informa una materia ya existente. Pero esto no significa que no le dé la existencia. Lo que significa es que hay que entender al Dios de Averroes más que como causa eficiente, como causa formal y final del mundo. Por eso dice en el Tahäfut: «dar la finalidad a los seres existentes separados de la materia es lo mismo que darles su existencia». ${ }^{94}$

En definitiva, podemos decir que para el mundo sensible la causalidad de Dios parece más bien ser formal que eficiente, mientras que en el mundo inteligible la acción divina se reduce a conferir a los cuerpos celestes su fin. Por todo lo dicho es evidente que el pensador cordobés no prescindió del Dios creador de la fe islámica. Como buen aristotélico, recuperó lo esencial de la enseñanża de Aristóteles sobre el origen del ser, y como sincero creyente musulmán preservó el dato revelado de la creación del mundo.

89 Compendio de Metafisica, ed. cit., pp. 84-85.

90 Tahāfut al-Tahāfut, ed. cit., p. 89.

91 Ibid., p. 34.

92 Fașl al-Maqāl, P. Manuel Alonso, Teología de Averroes, ed. cit., p. 176.

93 Tah̄ăfut al-Tahāfut, ed. cit., p. 97.

94 Ibid., p. 159. 